\title{
Undercooling Behavior and Critical Cooling Rate of Pd-Pt-Cu-P Alloy
}

\author{
Nobuyuki Nishiyama ${ }^{1}$, Kana Takenaka ${ }^{2}$, Takeshi Wada ${ }^{2}$, Hisamichi Kimura ${ }^{3}$ and Akihisa Inoue ${ }^{3}$ \\ ${ }^{1}$ RIMCOF Tohoku Univ. Lab., R\&D Institute of Metals and Composites for Future Industries, Sendai 980-8577, Japan \\ ${ }^{2}$ Graduate School, Tohoku University, Sendai 980-8577, Japan \\ ${ }^{3}$ Institute for Materials Research, Tohoku University, Sendai 980-8577, Japan
}

\begin{abstract}
In order to realize biomedical applications of bulk glassy alloys, we have developed new Pd-based glassy alloys with Ni-free composition in $\mathrm{Pd}-\mathrm{Pt}-\mathrm{Cu}-\mathrm{P}$ system and it is revealed that the highest glass-forming ability is obtained at a composition of $\mathrm{Pd}_{35} \mathrm{Pt}_{15} \mathrm{Cu}_{30} \mathrm{P}_{20}$. In addition, the alloy can be formed into bulk glassy rods with diameters of up to at least $30 \mathrm{~mm}$ by fluxed water quenching. In order to clarify the critical cooling rate for glass-formation, undercooling behavior and crystal growth rate are also discussed. Crystallization of the alloy under continuous cooling is mainly dominated by surface nucleation. Apparent crystal growth rate of the alloy at $0.73 T_{\mathrm{m}}$ is evaluated to be $5.2 \times 10^{-6} \mathrm{~m} \cdot \mathrm{s}^{-1}$ and this value is four orders of magnitude higher than that of previous $\mathrm{Pd}_{40} \mathrm{Cu}_{30} \mathrm{Ni}_{10} \mathrm{P}_{20}$ at the same degree of undercooling.
\end{abstract}

(Received August 5, 2005; Accepted September 21, 2005; Published December 15, 2005)

Keywords: bulk glassy alloys, biomedical applications, nickel-allergy, undercooling behavior, critical cooling rate

\section{Introduction}

Bulk glassy alloys have attracted much attention because of their useful characteristics, which are significantly different from those of crystalline alloys. ${ }^{1-4)}$ In particular, bulk glassy alloys are appropriate for biomedical applications due to their high strength, low Young's modulus, excellent corrosion resistance and viscous flow properties. Recently, Pd- and Pt-based bulk glassy alloys have drawn increasing interest as biomedical materials. Focusing on Pd-based bulk glassy alloys, a $\mathrm{Pd}-\mathrm{Cu}-\mathrm{Ni}-\mathrm{P}$ alloy can be formed into cylindrical glassy rod with a diameter of $72 \mathrm{~mm}^{5)}$ and the maximum size of the alloy may be enough to use biomedical or dental materials. However, the alloy contains an unsuitable element, that is $\mathrm{Ni}$, which will cause human allergy. In their application field, it is necessary to develop a Pd-based bulk glassy alloy without $\mathrm{Ni}$ element. Very recently, we have found that the partial replacement of $\mathrm{Pd}$ by $\mathrm{Pt}$ in $\mathrm{Pd}_{40} \mathrm{Cu}_{40} \mathrm{P}_{20}$ alloy is effective for the increases in maximum sample diameter and $\mathrm{Pd}-\mathrm{Pt}-\mathrm{Cu}-\mathrm{P}$ alloy with a particular composition can be formed into a cylindrical rod with a diameter of $30 \mathrm{~mm} .{ }^{6)}$ The newly developed alloy also shows high strength of $1410 \mathrm{MPa}$, high fracture strain of 0.017 and low Young's modulus of $83.0 \mathrm{GPa}$ under tensile load. These results suggest that the newly developed $\mathrm{Pd}-\mathrm{Pt}-\mathrm{Cu}-\mathrm{P}$ bulk glassy alloy can be regarded as a new type of Pd-based bulk glassy alloy, which is important for basic research and biomedical application. This paper presents undercooling behavior and critical cooling rate for glass-formation $\left(R_{\mathrm{c}}\right)$ of the new $\mathrm{Pd}-$ $\mathrm{Pt}-\mathrm{Cu}-\mathrm{P}$ bulk glassy alloy. Furthermore, nucleation behavior and crystal growth rate will be also discussed.

\section{Experimental Procedures}

A master ingot with a composition of $\mathrm{Pd}_{35} \mathrm{Pt}_{15} \mathrm{Cu}_{30} \mathrm{P}_{20}$ was prepared by arc melting the mixtures of pure- $\mathrm{Pd},-\mathrm{Ni}$, $-\mathrm{Cu}$ and pre-alloyed $\mathrm{Pd}-\mathrm{P}$ and $\mathrm{Pt}-\mathrm{P}$ in an argon atmosphere. In order to eliminate heterogeneous nuclei due to oxide contamination, a $\mathrm{B}_{2} \mathrm{O}_{3}$ flux treatment ${ }^{7)}$ was repeatedly carried out in a highly purified argon atmosphere (less than
$10 \mathrm{ppm}$ oxygen content) during alloy preparation. A highvacuum high-temperature DSC (Mac Science HV/HT-DSC) was employed in order to construct a Continuous-CoolingTransformation (CCT) diagram. Temperature deviation of the equipment from the cooling program was evaluated to be within $\pm 2.0 \mathrm{~K}$. Each spherical sample weighed $10 \pm 0.5 \mathrm{mg}$ to avoid the internal temperature gradient of sample during cooling measurement. The samples were initially heated to $1073 \mathrm{~K}$ at a heating rate of $0.67 \mathrm{~K} / \mathrm{s}$ and maintained at this temperature for $600 \mathrm{~s}$ to ensure complete melting. Then, the molten samples were cooled at different cooling rates $(R)$ ranging from 0.667 to $0.017 \mathrm{~K} / \mathrm{s}$. For constructing a CCT diagram, cooling DSC curves are analyzed in order to evaluate onset of crystallization temperature $\left(T_{\mathrm{x}}\right)$ and incubation time for crystallization $\left(t_{\mathrm{x}}\right)$. In order to determine accurate critical cooling rate for glass-formation $\left(R_{\mathrm{c}}\right)$, the cross-sectional structure of the samples was examined with an optical microscope (OM) using a polarized observation and micro-area X-ray diffraction.

\section{Results}

Figure 1 shows cooling DSC curves of the molten $\mathrm{Pd}_{35} \mathrm{Pt}_{15} \mathrm{Cu}_{30} \mathrm{P}_{20}$ alloy obtained at different $R$. A recalescence phenomenon due to crystallization can be clearly seen in each cooling DSC curve. Figure 2(a) summarizes the $T_{\mathrm{x}}$ as a function of $R$. A slight decrease in $T_{\mathrm{x}}$ with increasing $R$ can be seen. Figure 2(b) also summarizes the ratio of crystallization heat reduced by heat of fusion $\left(\Delta H_{x} / \Delta H_{f}\right)$ as a function of cooling rate. As seen in the figure, it is clear that the value of $\Delta H_{x} / \Delta H_{f}$ shows an asymptotic tendency to zero as according to the increasing $R$. These results suggest that the $R_{\mathrm{c}}$ of the alloy will be laid around $1 \mathrm{~K} / \mathrm{s}$, while the fully glassy sample could not be obtained even at the highest $R$ of $0.667 \mathrm{~K} / \mathrm{s}$.

Figure 3 shows the cross-sectional micrographs of the $\mathrm{Pd}_{35} \mathrm{Pt}_{15} \mathrm{Cu}_{30} \mathrm{P}_{20}$ samples solidified at various $R$. The sample solidified at $R$ of $0.017 \mathrm{~K} / \mathrm{s}$ is composed of only a single crystalline grain. In addition, it can be seen that the grain size drastically decreases and the number of crystalline grains 


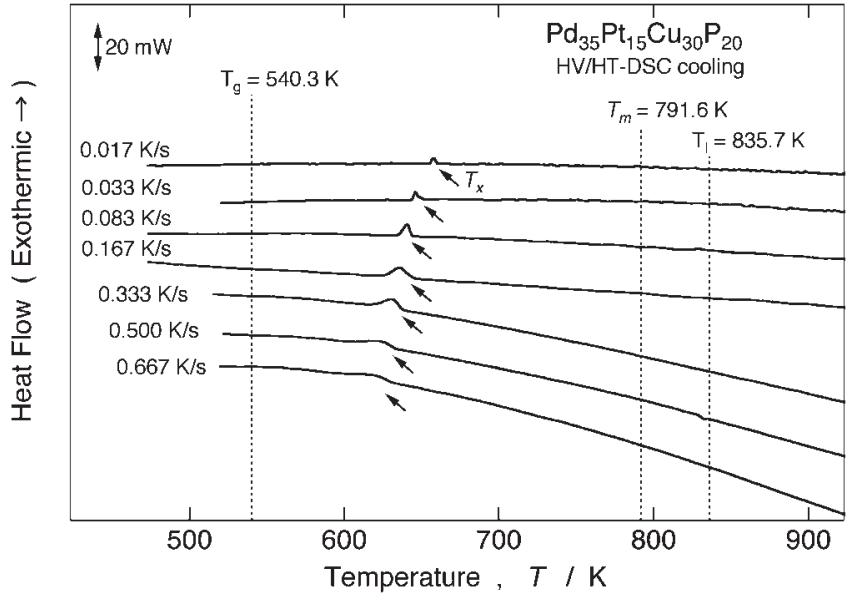

Fig. 1 Cooling DSC curves of the molten $\mathrm{Pd}_{35} \mathrm{Pt}_{15} \mathrm{Cu}_{30} \mathrm{P}_{20}$ alloy obtained at constant $R$ ranging from 0.667 to $0.017 \mathrm{~K} / \mathrm{s}$.

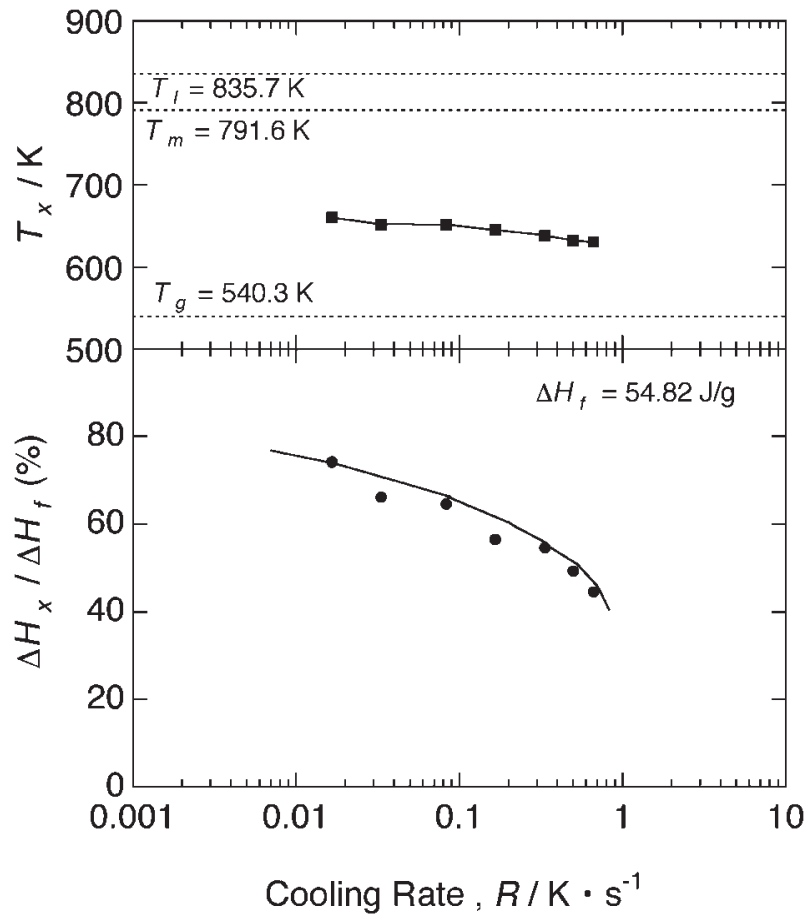

Fig. 2 (a) The on-set of recalescence temperature $\left(T_{\mathrm{x}}\right)$ as a function of $R$ and (b) the ratio of crystallization heat reduced by the heat of fusion $\left(\Delta H_{x} / \Delta H_{f}\right)$ as a function of $R$. increases with increasing $R$. Figure 4 shows the XRD patterns taken from the obtained samples, revealing that each crystalline grain is composed of $(\mathrm{Pd}, \mathrm{Pt})_{5} \mathrm{P}_{2},(\mathrm{Pd}, \mathrm{Pt})_{15} \mathrm{P}_{2}$, $(\mathrm{Pd}, \mathrm{Pt})_{3} \mathrm{P}$ and $\mathrm{CuPt}$ eutectic structure and no meta-stable phase is found. ${ }^{6)}$ Here, it is worth to note that the structure of the sample solidified at the highest $R$ of $0.667 \mathrm{~K} / \mathrm{s}$ contains a glassy region in the vicinity of the center of the sample. This result is consistent with the $R_{\mathrm{c}}$ estimation of around $1 \mathrm{~K} / \mathrm{s}$.

The relation between $T_{\mathrm{x}}$ and $R$ for the $\mathrm{Pd}_{35} \mathrm{Pt}_{15} \mathrm{Cu}_{30} \mathrm{P}_{20}$ alloy is plotted in a CCT diagram as shown in Fig. 5. The crystallization temperatures $T_{\mathrm{x}}$ for two kinds of $\mathrm{Pd}-\mathrm{Cu}-\mathrm{Ni}-\mathrm{P}$ alloys are also shown for comparison. Based on the $R_{\mathrm{c}}$ estimation of $1 \mathrm{~K} / \mathrm{s}$ for the $\mathrm{Pd}_{35} \mathrm{Pt}_{15} \mathrm{Cu}_{30} \mathrm{P}_{20}$ alloy, nose temperature $\left(T_{\mathrm{n}}\right)$ and incubation time $\left(t_{\mathrm{n}}\right)$ under constant cooling are assumed to be about $600 \mathrm{~K}$ and $200 \mathrm{~s}$, respectively. One can notice that the undercooling for the

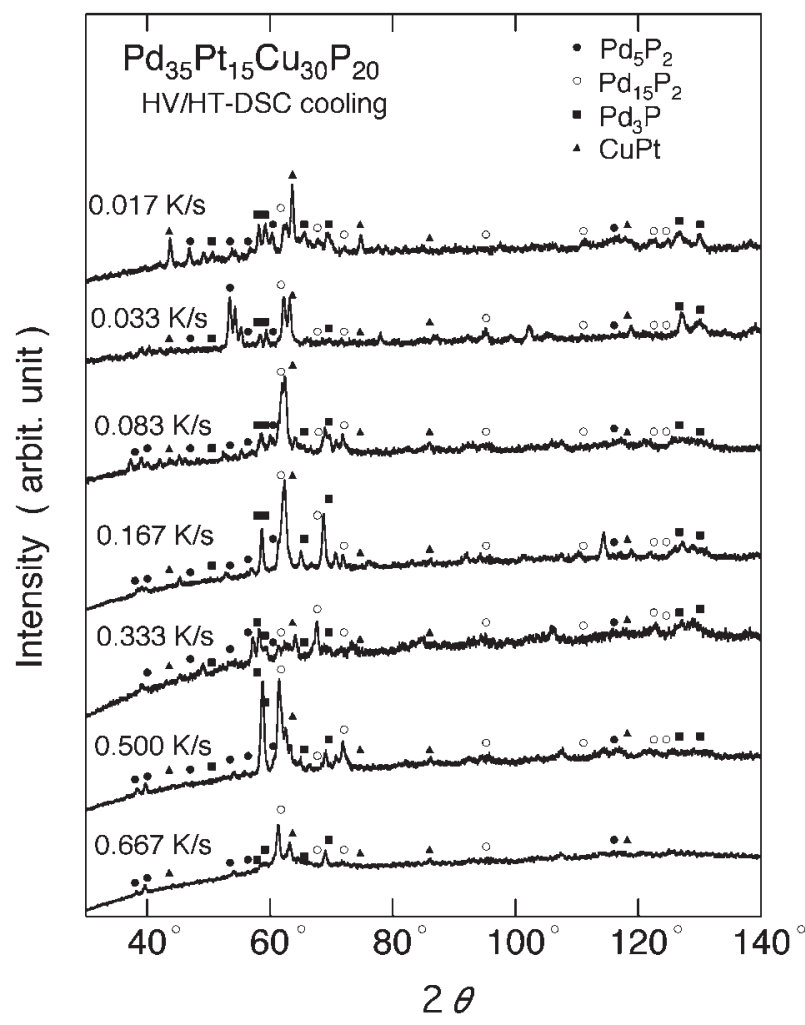

Fig. 4 XRD patterns of the $\mathrm{Pd}_{35} \mathrm{Pt}_{15} \mathrm{Cu}_{30} \mathrm{P}_{20}$ samples solidified at various constant $R$.

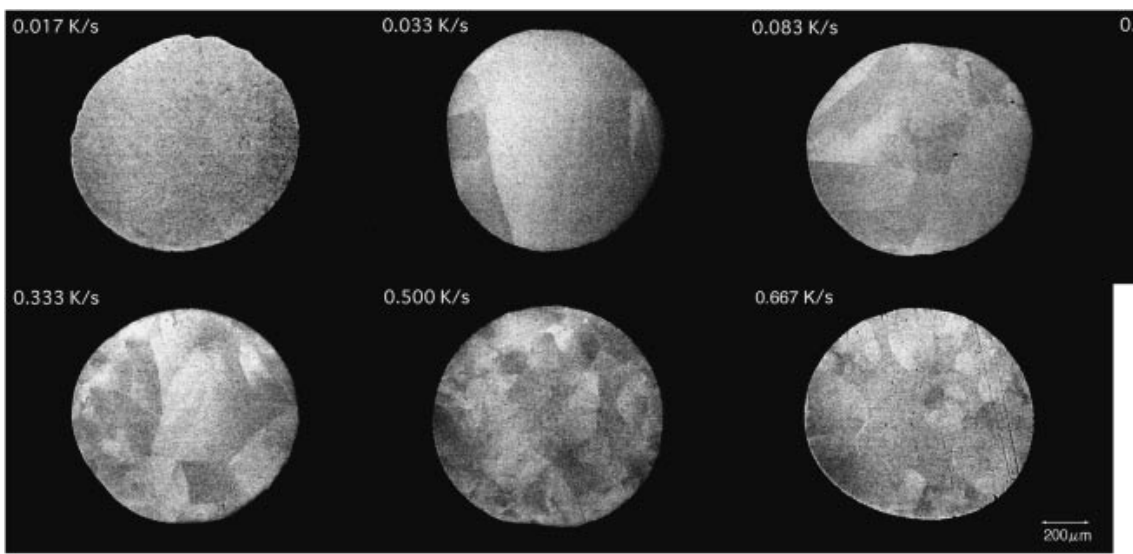

Fig. 3 Cross-sectional micrographs of the $\mathrm{Pd}_{35} \mathrm{Pt}_{15} \mathrm{Cu}_{30} \mathrm{P}_{20}$ samples solidified at various constant $R$. 


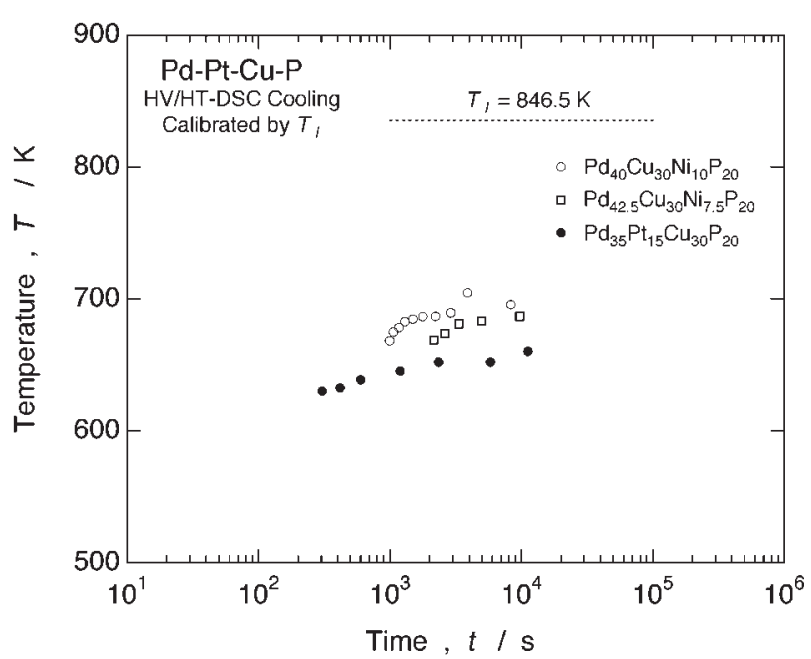

Fig. 5 CCT diagram for the $\mathrm{Pd}_{35} \mathrm{Pt}_{15} \mathrm{Cu}_{30} \mathrm{P}_{20}$ alloy constructed under various constant $R$.

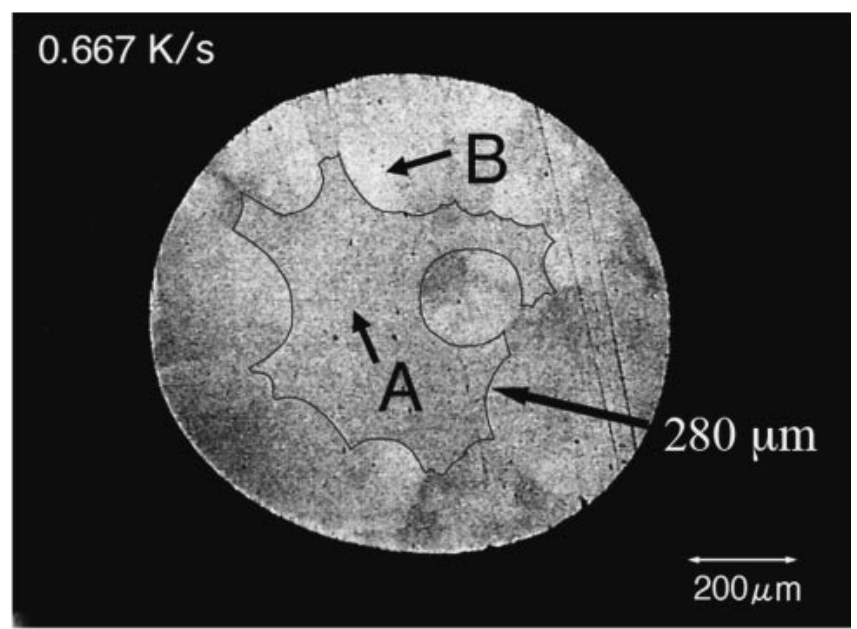

Fig. 6 Enlarged cross-sectional micrograph of the $\mathrm{Pd}_{35} \mathrm{Pt}_{15} \mathrm{Cu}_{30} \mathrm{P}_{20}$ sample solidified at $0667 \mathrm{~K} / \mathrm{s}$.

$\mathrm{Pd}_{35} \mathrm{Pt}_{15} \mathrm{Cu}_{30} \mathrm{P}_{20}$ alloy is much deeper than those for the $\mathrm{Pd}-$ $\mathrm{Cu}-\mathrm{Ni}-\mathrm{P}$ alloys, while the liquidus temperature $\left(T_{1}\right)$ of the $\mathrm{Pd}_{35} \mathrm{Pt}_{15} \mathrm{Cu}_{30} \mathrm{P}_{20}$ alloy $(847 \mathrm{~K})$ is almost the same as those for the $\mathrm{Pd}-\mathrm{Cu}-\mathrm{Ni}-\mathrm{P}$ alloys ( 834 and $848 \mathrm{~K}$ ). This result suggests that the nucleation frequency for the $\mathrm{Pd}_{35} \mathrm{Pt}_{15} \mathrm{Cu}_{30} \mathrm{P}_{20}$ alloy is much smaller than those for the $\mathrm{Pd}-\mathrm{Cu}-\mathrm{Ni}-\mathrm{P}$ alloys. On the other hand, the grain size of crystals shown in the Fig. 3 is much larger than that for the $\mathrm{Pd}-\mathrm{Cu}-\mathrm{Ni}-\mathrm{P}$ alloys reported previously ${ }^{8)}$ even at the same $R$. Therefore, it can be said that the grain growth of the $\mathrm{Pd}_{35} \mathrm{Pt}_{15} \mathrm{Cu}_{30} \mathrm{P}_{20}$ alloy will be much faster than that of $\mathrm{Pd}-\mathrm{Cu}-\mathrm{Ni}-\mathrm{P}$ alloy. However, it is concluded that the low $R_{\mathrm{c}}$ of about $1 \mathrm{~K} / \mathrm{s}$ and the formation of a bulk glassy rod with a diameter of $30 \mathrm{~mm}$ in Ref. 6) are quite useful for biomedical applications.

\section{Discussion}

Here, we discuss about the nucleation behavior and crystal growth rate of the alloy. Figure 6 shows enlarged crosssectional micrographs of the $\mathrm{Pd}_{35} \mathrm{Pt}_{15} \mathrm{Cu}_{30} \mathrm{P}_{20}$ samples

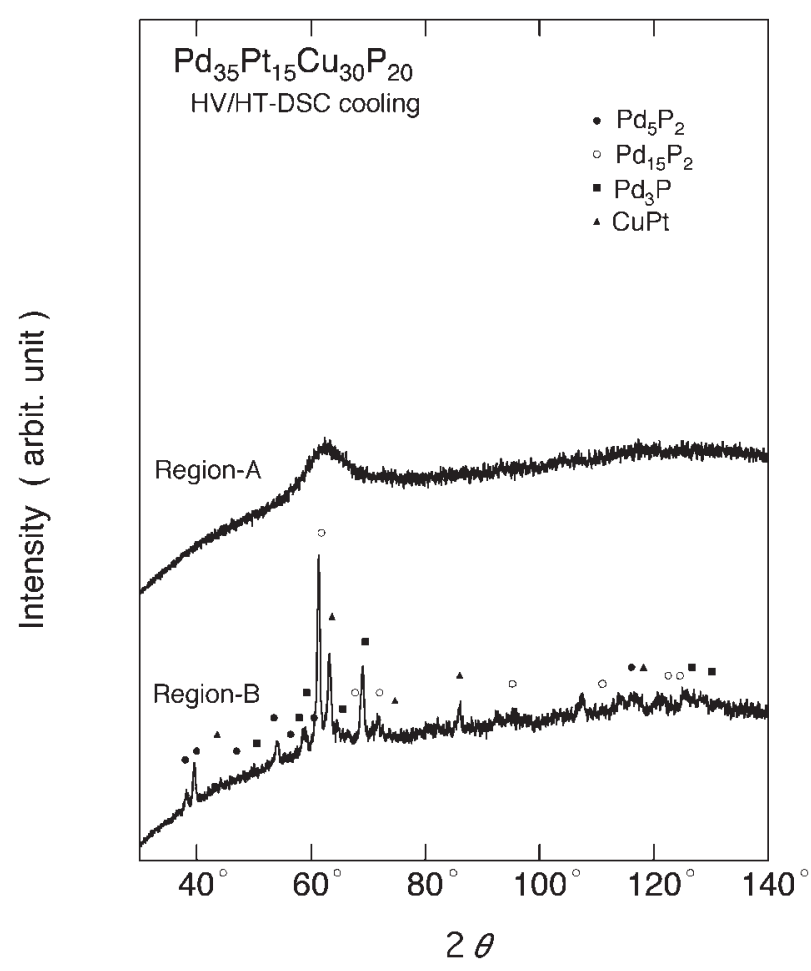

Fig. 7 Micro XRD patterns taken from regions corresponding A and B in the Fig. 8.

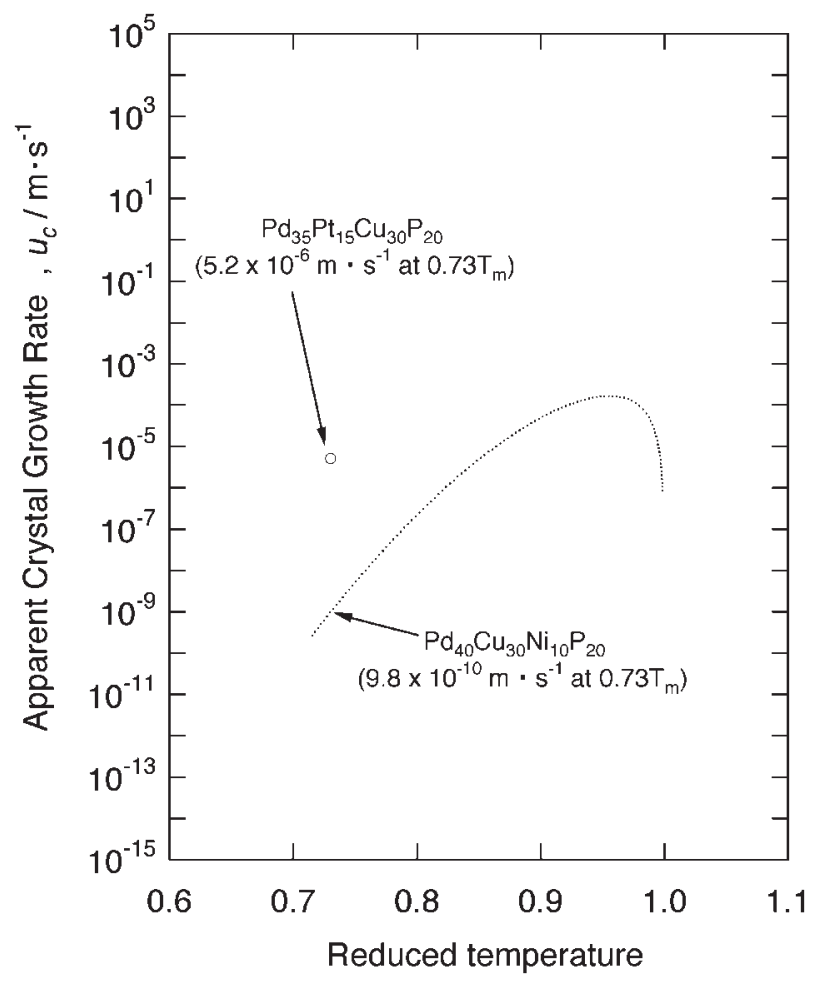

Fig. 8 A relationship between apparent crystal growth rate (uc) and reduced temperature for the undercooled $\mathrm{Pd}_{35} \mathrm{Pt}_{15} \mathrm{Cu}_{30} \mathrm{P}_{20}$ alloy. The previous result for $\mathrm{Pd}_{40} \mathrm{Cu}_{30} \mathrm{Ni}_{10} \mathrm{P}_{20}$ alloy is also plotted for comparison.

solidified at $0.667 \mathrm{~K} / \mathrm{s}$. The structure of the sample can be clearly divided into two parts represented futureless A and B with some contrast regions. Corresponding micro XRD patterns are given in Fig. 7. As seen in the figure, the micro 
XRD pattern taken from the A-region is consist of only halo pattern, revealing that the central region of the sample is composed of glassy phase. On the other hand, the pattern from the B-region can be identified as $(\mathrm{Pd}, \mathrm{Pt})_{5} \mathrm{P}_{2}$, $(\mathrm{Pd}, \mathrm{Pt})_{15} \mathrm{P}_{2},(\mathrm{Pd}, \mathrm{Pt})_{3} \mathrm{P}$ and $\mathrm{CuPt}$ phases. Taking the micro $\mathrm{XRD}$ pattern taken from only single crystal grain into account, each crystal grains are precipitated an eutectic manner. In addition, the crystallization of the sample is mainly dominated by surface nucleation. The longest crystal growth distance is evaluated to be $280 \mu \mathrm{m}$ (represented with arrow). As seen the cooling DSC curve at a rate of $0.667 \mathrm{~K} /$ sin Fig. 1, the time during crystallization completing and reduced crystallization temperature are estimated to be $54 \mathrm{~s}$ and $0.73 T_{\mathrm{m}}$, respectively. These values are plotted as a relationship between apparent crystal growth rate $\left(u_{\mathrm{c}}\right)$ and reduced temperature in Fig. 8. Previous result for $\mathrm{Pd}_{40} \mathrm{Cu}_{30} \mathrm{Ni}_{10} \mathrm{P}_{20}$ alloy is also plotted for comparison. At the same reduced temperature (at $0.73 T_{\mathrm{m}}$ ), $u_{\mathrm{c}}$ for the undercooled $\mathrm{Pd}_{35} \mathrm{Pt}_{15} \mathrm{Cu}_{30} \mathrm{P}_{20}$ alloy $\left(9.8 \times 10^{-10} \mathrm{~m} \cdot \mathrm{s}^{-1} \mathrm{c}\right)$. This four orders of magnitude difference in crystal growth rate causes twelve orders of magnitude difference in volume fraction of crystals. It is therefore concluded that the difference in $R_{\mathrm{c}}$ for the $\mathrm{Pd}-\mathrm{Pt}-\mathrm{Cu}-\mathrm{P}$ and $\mathrm{Pd}-\mathrm{Cu}-\mathrm{Ni}-\mathrm{P}$ alloys is attributed to the difference in crystal growth rate.

\section{Conclusions}

Undercooling behavior and critical cooling rate for glassformation for the $\mathrm{Pd}_{35} \mathrm{Pt}_{15} \mathrm{Cu}_{30} \mathrm{P}_{20}$ alloy were investigated. As a result, the critical cooling rate for glass-formation of the alloy is estimated to be about $1 \mathrm{~K} / \mathrm{s}$. It is also found that the grain growth rate of the alloy is much higher than that of $\mathrm{Pd}-$ $\mathrm{Cu}-\mathrm{Ni}-\mathrm{P}$ alloy. However, the highly processable feature due to the high glass-forming ability of the alloy is applicable for biomedical applications.

\section{REFERENCES}

1) A. Inoue: Mater. Trans., JIM 36 (1995) 866-875.

2) A. Inoue: Acta Mater. 48 (2000) 279-306.

3) A. Inoue: Mater. Sci. Eng. A 304-306 (2001) 1-10.

4) Supercooled Liquid Bulk Glassy and Nanocrystalline State of Alloys, ed. by A. Inoue, A. R. Yavari, W. L. Johnson and R. H. Dauskardt, (MRS, warrendale, 2001) pp. L12.13.1-6.

5) A. Inoue, N. Nishiyama and T. Matsuda: Mater. Trans., JIM 37 (1996) 181-184.

6) K. Takenaka, T. Wada, N. Nishiyama, H. M. Kimura and A. Inoue: Mater. Trans. 46 (2005) 1720-1724.

7) H. W. Kui, A. L. Greer and D. Turnbull: Appl. Phys. Lett. 45 (1984) 615-616.

8) N. Nishiyama and A. Inoue: Mater. Trans., JIM 38 (1997) 464-472. 